\title{
Methodology Development for Investigation of Slurry Abrasion Corrosion by Integrating an Electrochemical Cell to a Miller Tester
}

\author{
Sheng-Hui Wang $\cdot$ Jiaren Jiang $\cdot$ Margaret M. Stack
}

Received: 18 November 2014/Revised: 26 January 2015/ Accepted: 29 January 2015/Published online: 13 February 2015

(C) Her Majesty the Queen in Right of Canada as represented by the National Research Council Canada 2015

\begin{abstract}
Material losses in slurry handling systems constitute a significant fraction of cost in oil sands, mining, and mineral processing operations. It is thus important to better understand wear attack mechanisms and major factors affecting wear in such applications. In this work, a methodology and a testing system have been developed to study the abrasion-corrosion synergism during slurry abrasion based on a Miller test machine by incorporating a three-electrode electrochemical cell. The proposed methodology has then been validated experimentally using QT 100 steel. It has been shown that cathodic protection using such system setup is effective in suppressing the corrosion effect on the total material loss. In general, corrosion-induced enhancement on slurry abrasion loss rate increases with slurry corrosivity but inversely with sliding speed.
\end{abstract}

Keywords Slurry abrasion - Abrasion-corrosion . Tribo-corrosion $\cdot$ Miller tester

S.-H. Wang $(\square) \cdot$ J. Jiang $(\square)$

Mining Wear and Corrosion Lab, Energy, Mining and Environment Portfolio, National Research Council Canada, 4250 Wesbrook Mall, Vancouver, BC V6T 1W5, Canada e-mail: sheng-hui.wang@nrc-cnrc.gc.ca

J. Jiang

e-mail: jiaren.jiang@nrc-cnrc.gc.ca

M. M. Stack

Department of Mechanical Engineering, University of Strathclyde, 75 Montrose St., Glasgow G1 1XJ, UK

\section{Introduction}

Slurry abrasion is commonly encountered in slurry handling equipment used in the oil sands, mining, and mineral processing operations, such as slurry pumps, separation vessels, and hydrotransport pipelines. The related cost on equipment maintenance and production interruption can be very significant. There are thus strong demands from the industry to better understand the underlining slurry abrasion mechanisms and to find practical solutions for mitigating the related severe damages.

Wear mechanisms in slurry handling systems are fairly complex and are not fully understood. Nevertheless, corrosion is almost always involved in the slurry abrasion of such systems because the water used in most of the processes typically contains various types of corrosive species, such as chlorides and other species from the minerals being processed as well as from the processing agents [1-4]. Many researches have shown that synergistic effect can significantly increase the total materials loss under combined wear and corrosion attacks in different wear or erosion systems [1, 2, 5-13]. In the past two decades or so, extensive researches have been dedicated to the so-called tribo-corrosion phenomena and remarkable progresses have been made in understanding the synergistic effect [14-25]. However, so far there is still a lack of effective evaluation tools for the study of abrasion-corrosion in slurry abrasion and little has been done to address the practically important issue [26].

Among few available laboratory testing methods for slurry abrasion studies, Miller tester is an established tool for evaluating the slurry abrasivity as well as for ranking the wear performance of materials in given slurry conditions [27]. In this work, a Miller tester has been modified to establish a methodology for investigating the slurry 
abrasion-corrosion synergism. A preliminary investigation has been performed on a QT 100 steel to validate the methodology and to have a brief insight into corrosioninduced enhancement to wear rate of the steel during slurry abrasion.

\section{Methodology Development}

\subsection{The Miller Tester and the Testing Methodology}

The testing methodology is developed based on a Miller tester, which was constructed in conformity to the ASTM G75 standard [27], as shown in Fig. 1a. The tester has four parallel identical testing cells. Each cell consists of a slurry bath and a reciprocating arm with a stroke of $203 \mathrm{~mm}$, as schematically shown in Fig. 1b. A wear specimen having a testing surface area of $12.7 \mathrm{~mm} \times 25.4 \mathrm{~mm}$ is installed on a specimen holder attached to the arm and is loaded against a neoprene rubber lap at the bottom of the slurry bath. More detailed description of the test machine can be referred to the ASTM G75 standard. It should be noted that wear of the neoprene rubber lap is very minimal during slurry abrasion tests, which has little effect on wear of the test specimens. The same wear rate was observed whether when the rubber lap was new or after it had been used for several test runs in previous work.
In order to acquire the individual contributions of abrasion, corrosion, and synergy, an in situ three-electrode electrochemical corrosion cell is implemented in the Miller tester as shown in Fig. 2a. The working electrode (i.e., the specimen) immersed in the testing slurry and the counter electrode are connected to a potentiostat. A reference electrode (in this case, a saturated calomel electrode) is placed in a holder that is fixed on the pivoted reciprocating arm and travels together with the wear specimen.

The holder for the reference electrode is filled with $1 \mathrm{M}$ potassium chloride solution, which is bridged to the testing slurry by a plastic tube filled with $1 \mathrm{M}$ potassium chloride gellified with agar as shown more clearly in Fig. 2b. The end of the plastic tube salt bridge is fixed on to the specimen holder and is placed as close as possible to the testing surface of the wear specimen. The in situ electrochemical cell is schematically shown in Fig. 2c. For convenience, the stainless steel body of the slurry trough (which is isolated from the specimen by the neoprene rubber lap) was used as the counter electrode; by doing so, the electrolyte impedance between the counter electrode and the specimen was not affected much by specimen traveling. As the surface area of the counter electrode (the internal surface of the stainless steel trough) was much larger than the testing surface of the specimen, the anodic current density on the counter electrode should be negligible under applied cathodic protection $(\mathrm{CP})$ potentials. In addition, due to the
Fig. 1 The Miller testing machine (a) and schematic diagram showing the working principle (b)

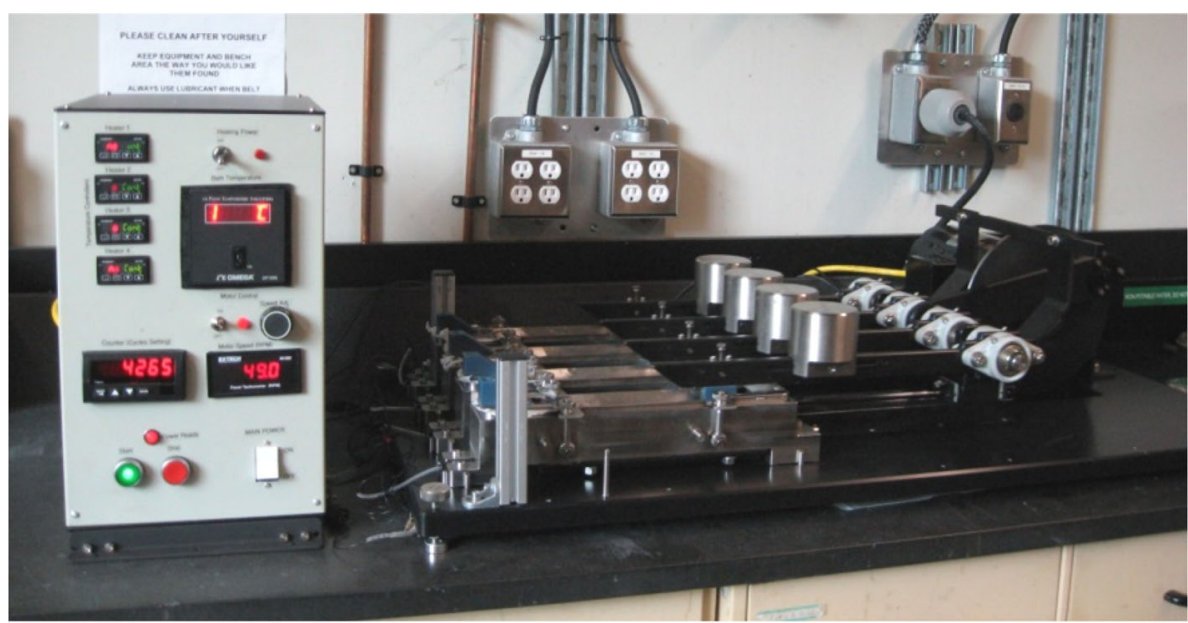

(a)

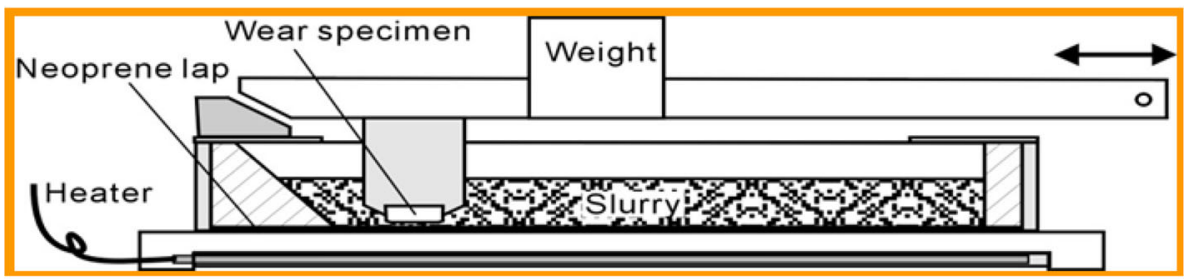

(b) 


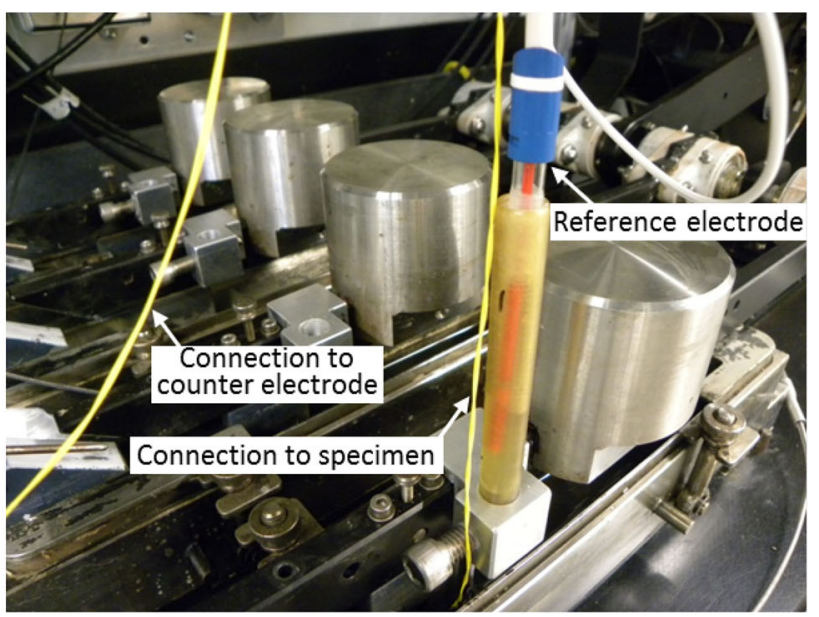

(a)

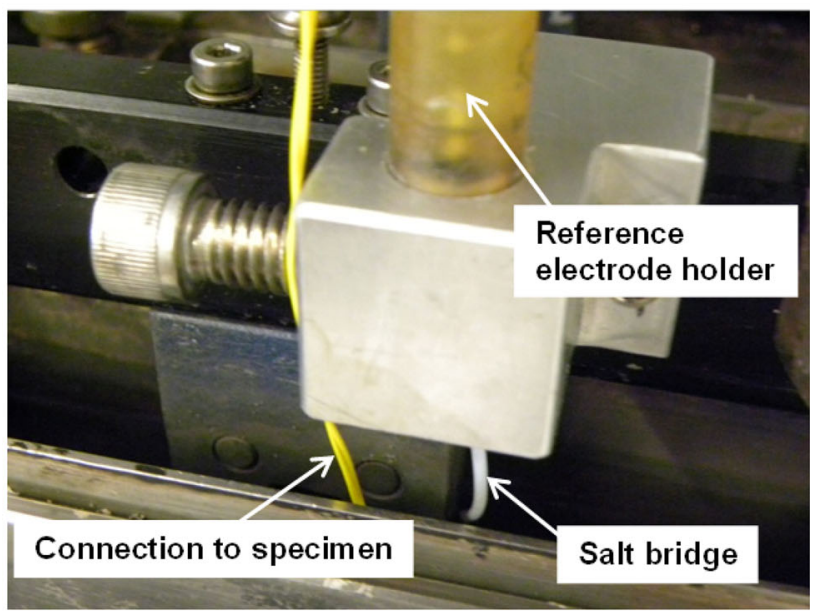

(b)

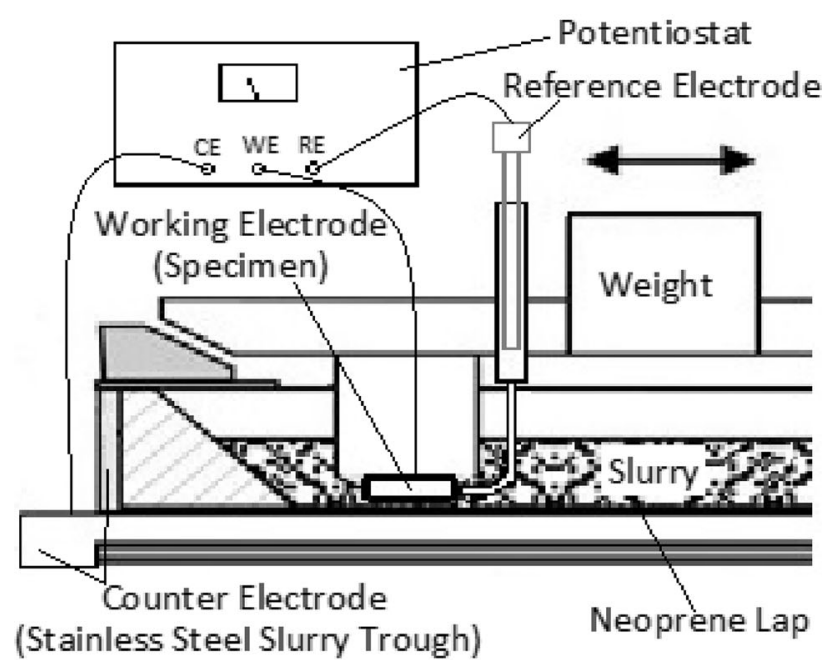

(c)

Fig. 2 Setup of the in situ electrochemical cell (a), the salt bridge from the reference electrode holder to the testing slurry (b), and schematic diagram (c) passive nature of the stainless steel at the polarization levels involved as well as the benign nature of slurries, there should be no notable increase in ionic concentration of the slurry as a result of anodic dissolution of the counter electrode. That is to say that the electrochemical behavior of a testing specimen should not be affected while employing the stainless steel body of the slurry trough as the counter electrode. Alternatively, platinum or carbon counter electrode, which should be traveling with the testing specimen, could be employed for the tests.

Using this set up, slurry abrasion testing can be performed both with and without CP to investigate the abrasion-corrosion synergy as per the ASTM G119 Standard Guide [28].

For specimens to be tested under CP (for abrasion-only loss measurement), a connection wire is first spot-welded on the back surface of the specimen opposite to the test surface (Fig. 3a). Then, the surfaces other than the testing surface (i.e., the bottom of the specimen) are coated with an isolation paint to eliminate corrosion from the nontesting surfaces (Fig. 3b). To prevent the damage of the isolation coating during the abrasion testing (on the side surfaces), the specimen is further protected with a shrinkable plastic tube (Fig. 3c).

\subsection{Slurry Abrasion Response (SAR) Number Calculation}

Based on ASTM G75 standard [27], the wear rate of the material is expressed using the SAR number, which is defined by

$\mathrm{SAR}=18.18\left(\left.\frac{\mathrm{d} M}{\mathrm{~d} t}\right|_{t=2 \mathrm{~h}}\right)\left(\frac{7.58}{\rho_{\text {sample }}}\right)$,

where $\rho_{\text {sample }}$ is the density of the material under investigation, and $M$ (in $\mathrm{mg}$ ) the cumulative mass loss at different sliding times, $t$ (in h).

The definition for SAR number in Eq. (1) is for sliding at the standard speed of $48 \mathrm{rpm}$. The cumulative mass loss, $M$, is obtained by measuring sample mass changes at three equally spaced $2 \mathrm{~h}$ testing intervals, i.e., at a total/accumulated sliding time, $t$, of 2,4 , and $6 \mathrm{~h}$, respectively. A curve fitting is conducted for a relationship (Eq. 2) between the cumulative mass loss, $M$, and sliding time, $t$, from which the mass loss rate, $\mathrm{d} M /\left.\mathrm{d} t\right|_{t=2} \mathrm{~h}$, at $2 \mathrm{~h}$ sliding is obtained and used for the calculation of SAR number in Eq. (1):

$M=A t^{B}$,

where $A$ and $B$ are fitting constants. 

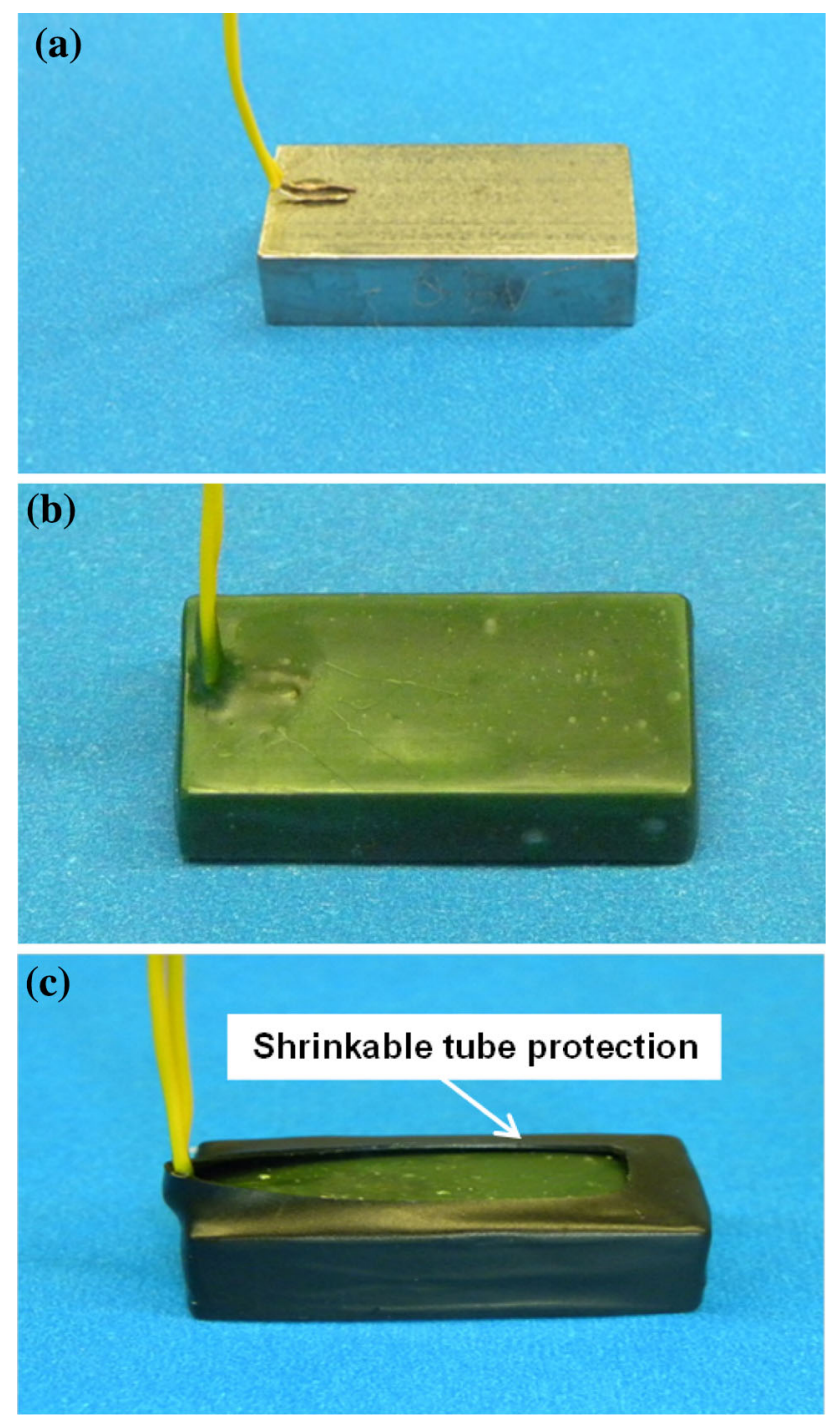

Fig. 3 Wear specimen preparation for testing under cathodic protection

\section{Experimental Validation of the Methodology}

\subsection{Experimental Details}

For validation of the methodology, a preliminary experimental study was performed on QT 100 steel using the testing system. The material has chemical composition (in wt \%) of $0.175 \mathrm{C}-0.230 \mathrm{Si}-1.000 \mathrm{Mn}-0.022 \mathrm{P}-0.010$ $\mathrm{S}-0.570 \mathrm{Cr}-0.177 \mathrm{Mo}$ (balance $\mathrm{Fe}$ ), and is a type of quenched and tempered steel, similar to ASTM A514. Its hardness value is $28.7 \mathrm{HRC}$ (equivalent to $283 \mathrm{HV}$ ). The specimen testing surface was prepared by fine grinding with a surface roughness $\left(R_{\mathrm{a}}\right)$ of about $0.3 \mu \mathrm{m}$.

The testing slurry is made of AFS 50/70 silica sand and a liquid. The liquid for making the slurry is either deionized (DI) water or $3.5 \% \mathrm{NaCl}$ (salt) solution. Two slurry concentrations, $50 \mathrm{wt} \%$ of sand $(150 \mathrm{~g}$ sand $+150 \mathrm{~mL}$ liquid) and $10 \mathrm{wt} \%$ of sand $(20 \mathrm{~g}$ sand $+180 \mathrm{ml}$ liquid) respectively, are used. Slurry $\mathrm{pH}$ value was monitored before the onset of each test. The $\mathrm{pH}$ is around 7.1-7.2 for all the slurry compositions.

The sliding speed is either $48 \mathrm{rpm}(0.325 \mathrm{~m} / \mathrm{s}$, the standard speed as per ASTM Standard) or $16 \mathrm{rpm}$ $(0.108 \mathrm{~m} / \mathrm{s})$. The load on the wear specimen is $22.2 \mathrm{~N}$. For specimens tested at the speed of $48 \mathrm{rpm}$, the test lasted for a total of $6 \mathrm{~h}$, and the mass loss was measured after every $2 \mathrm{~h}$ of testing. When using the sliding speed of $16 \mathrm{rpm}$, the total test duration lasted for $18 \mathrm{~h}$, and mass loss of the specimen was measured after every $6 \mathrm{~h}$ of testing. Therefore, the total sliding distance (or cycles of sliding), as well as that between two measurements, is kept the same independent of the sliding speed. The total sliding cycles are 17,280 cycles in both cases.

To make the results comparable, equivalent SAR numbers are obtained for the sliding speed of $16 \mathrm{rpm}$, and each time interval of $6 \mathrm{~h}$ at $16 \mathrm{rpm}$ is considered equivalent to $2 \mathrm{~h}$ at $48 \mathrm{rpm}$.

For wear testing under $\mathrm{CP}$, the specimen was immersed into the slurry and kept at the ready position for $10 \mathrm{~min}$ while the open circuit potential was measured. A cathodic potential of $0.5 \mathrm{~V}$ more negative to the open circuit potential was then applied before starting the slurry abrasion testing.

\subsection{Results and Discussion}

The cumulative mass losses versus the cycles of sliding are shown in Fig. 4, based on which the respective SAR number has been calculated and listed in Table 1 .

It can be seen that the abrasive wear rates (as expressed by the SAR numbers) are dependent on the slurry corrosivity (DI water or salt solution), concentration of solids in slurry, and sliding speed. Overall, it is evident that the abrasive wear rate increases with slurry concentration and corrosivity but inversely with sliding speed.

As shown in Fig. 4, after the CP is applied, cumulative mass loss is significantly reduced, and the large difference observed without CP is mostly eliminated. This is a strong indication that wear mass loss is mostly due to pure mechanical abrasion under CP. It should be noted that, under $\mathrm{CP}$, the cumulative mass losses are slightly higher in slurry of DI water than those in slurry of salt solution of similar solid particle concentration; this is because the $\mathrm{CP}$ is less effective in slurry of DI water, due to lower electrolyte conductivity. In fact, lower cathodic polarization current was observed in slurry with DI water. It should be mentioned that no influence on corrosion comes from slurry $\mathrm{pH}$, which was almost neutral in all cases; the initial surface finish should have no measurable effect on the SAR 
(a)

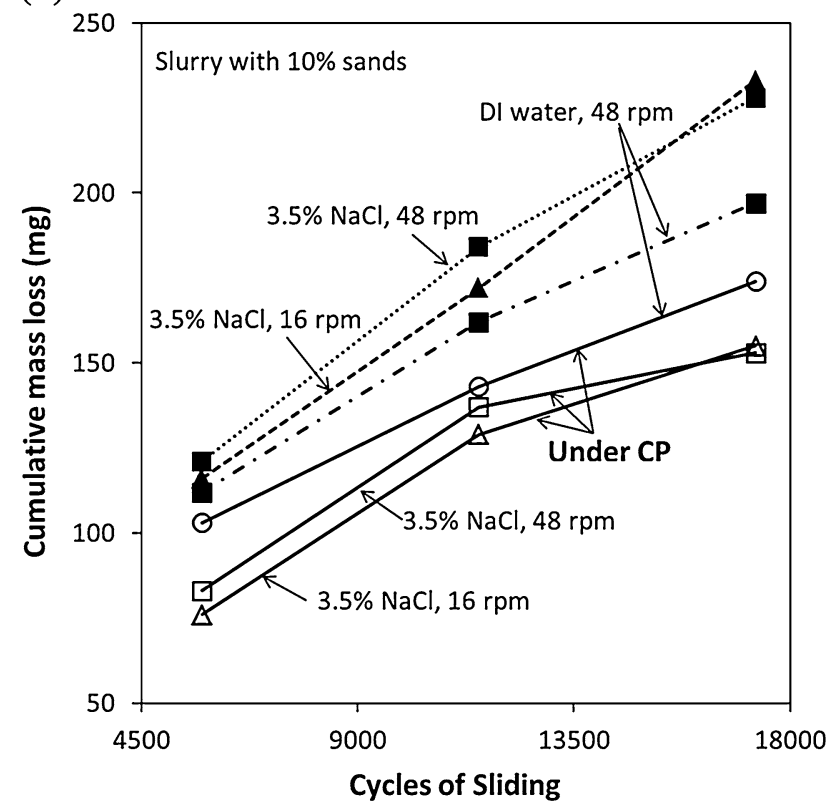

(b)

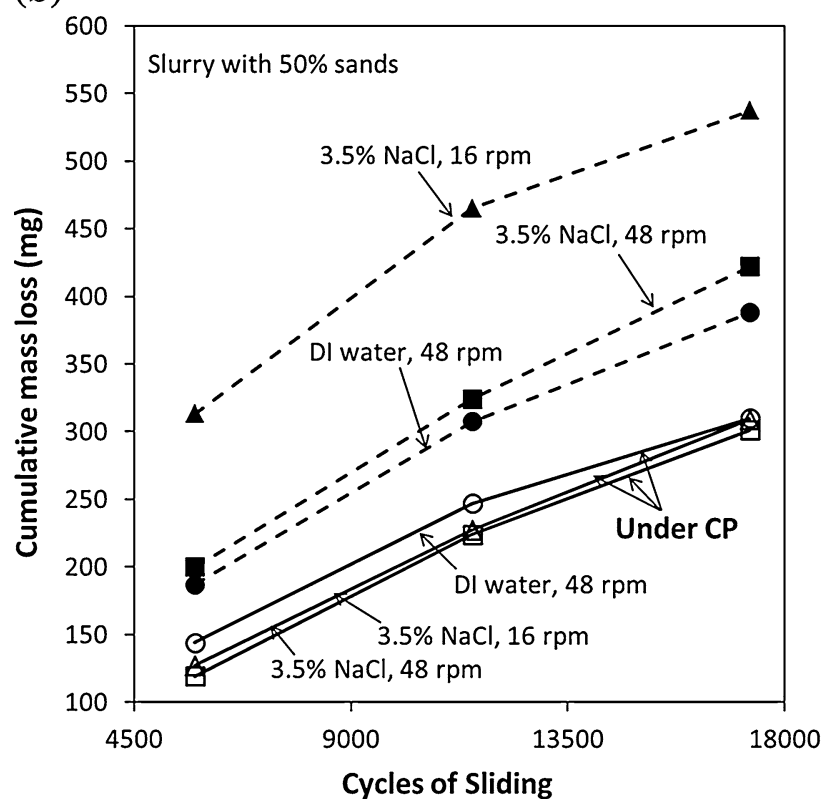

Fig. 4 Reduction of cumulative mass loss (versus the cycles of sliding) under cathodic protection

number, as it was rapidly replaced by the fully abraded surface for all the tested specimens.

Considering a general tribo-corrosion system, the total wear rate, $T$, can be considered as a sum of pure mechanical wear loss rate, $W_{0}$, corrosion rate in the absence of wear, $C_{0}$, and the synergistic component, $S$, as follows [28]:

$T=W_{0}+C_{0}+S$.

The pure corrosion loss rate, $C_{0}$, can be easily measured in a separate corrosion cell using electrochemical method.
With the above established abrasion-corrosion test system, the total wear rate, $T$, can be measured during sliding abrasion tests without $\mathrm{CP}$, while the pure mechanical wear loss rate, $W_{0}$, can be obtained under CP. On that basis, the total synergy, $S$, can be derived. The wear rate can be well reflected by the corresponding SAR numbers.

In the above-analysis, the sum of pure corrosion rate and the synergistic component, i.e., $C_{0}+S$, was combined together and reported in Table 1 as a contribution of corrosion to the total material loss rates, i.e., the "SAR enhancement ratio by corrosion". In fact, the pure corrosion rate is very low: As estimated with electrochemical measurements, the corrosion rate on equivalent testing surface area is about $0.0041 \mathrm{mg} / \mathrm{h}$ in DI water with $10 \%$ of sands, and $0.082 \mathrm{mg} / \mathrm{h}$ in salt solution with $10 \%$ of sands, respectively. Assuming that the corrosion rate is constant, the mass loss due to pure corrosion will be only about $0.024 \mathrm{mg}$ at the end of tests with $48 \mathrm{rpm}$ in DI water with $10 \%$ sands, and 0.49 and $1.47 \mathrm{mg}$, respectively, at the end of tests with 48 and $16 \mathrm{rpm}$ in salt solutions with $10 \%$ of sands. Compared to the total cumulative mass loss as reported in Fig. 4a, the contribution of pure corrosion could be neglected.

The effectiveness of $\mathrm{CP}$ eliminating corrosion contribution to the wear loss rate (i.e., $C_{0}+S$ ) can also be seen from the results listed in Table 1. Under CP, the SAR number (i.e., the wear rate) seems to be only a function of sand concentration in the slurry and is independent of the slurry corrosivity and sliding speed.

When testing was conducted in the low corrosivity slurry with DI water, the SAR enhancement ratio by corrosion is only about $10 \%$ with slight differences depending on the solid concentration in the slurry (Table 1).

If the slurry is made of the salt solution, the slurry corrosivity is significantly higher. In fact, the pure corrosion rate is enhanced by a factor of 20 as compared to that in slurries with DI water. This may be due to the fact that, in contrast to the extremely low conductivity of slurry with DI water, slurry with salt solution has significantly higher electrolyte conductivity, promoting electrochemical corrosion. In addition, $\mathrm{Cl}^{-}$species may play a role as well.

Sliding speed also showed evident effect on the total material loss as well as on the relative contribution of corrosion. Slower sliding seems to increase the SAR enhancement ratio by corrosion.

With regard to effect of solid concentration in the slurry, both the total material loss rates and pure mechanical wear rate are much lower for a slurry with lower solid concentration (i.e., for the slurry with $10 \%$ of sands as compared to the one with $50 \%$ of sands), but the difference in SAR enhancement ratio by corrosion is less significant.

Wear surfaces after testing under the various conditions are relatively flat, as shown in Figs. 5 and 6. Some local 
Table 1 SAR numbers under different testing conditions and the SAR enhancement ratio by corrosion

\begin{tabular}{|c|c|c|c|c|c|c|}
\hline \multirow[t]{2}{*}{ Condition or note } & \multicolumn{3}{|c|}{ Slurry with $50 \%$ sands } & \multicolumn{3}{|c|}{ Slurry with $10 \%$ of sands } \\
\hline & $\begin{array}{l}\text { DI water, } \\
48 \mathrm{rpm}\end{array}$ & $\begin{array}{l}3.5 \% \mathrm{NaCl}, \\
48 \mathrm{rpm}\end{array}$ & $\begin{array}{l}3.5 \% \mathrm{NaCl}, \\
16 \mathrm{rpm}\end{array}$ & $\begin{array}{l}\text { DI Water, } \\
48 \mathrm{rpm}\end{array}$ & $\begin{array}{l}3.5 \% \mathrm{NaCl}, \\
48 \mathrm{rpm}\end{array}$ & $\begin{array}{l}3.5 \% \mathrm{NaCl}, \\
16 \mathrm{rpm}\end{array}$ \\
\hline Without CP & 1026 & 1238 & 1409 & 526 & 625 & 683 \\
\hline With CP & 943 & 944 & 961 & 458 & 436 & 463 \\
\hline $\begin{array}{l}\text { Contribution ratio of pure } \\
\text { mechanical wear }(\%)\end{array}$ & 92 & 76 & 68 & 87 & 70 & 68 \\
\hline $\begin{array}{l}\text { SAR enhancement ratio } \\
\text { by corrosion }(\%)\end{array}$ & 8 & 24 & 32 & 13 & 30 & 32 \\
\hline
\end{tabular}
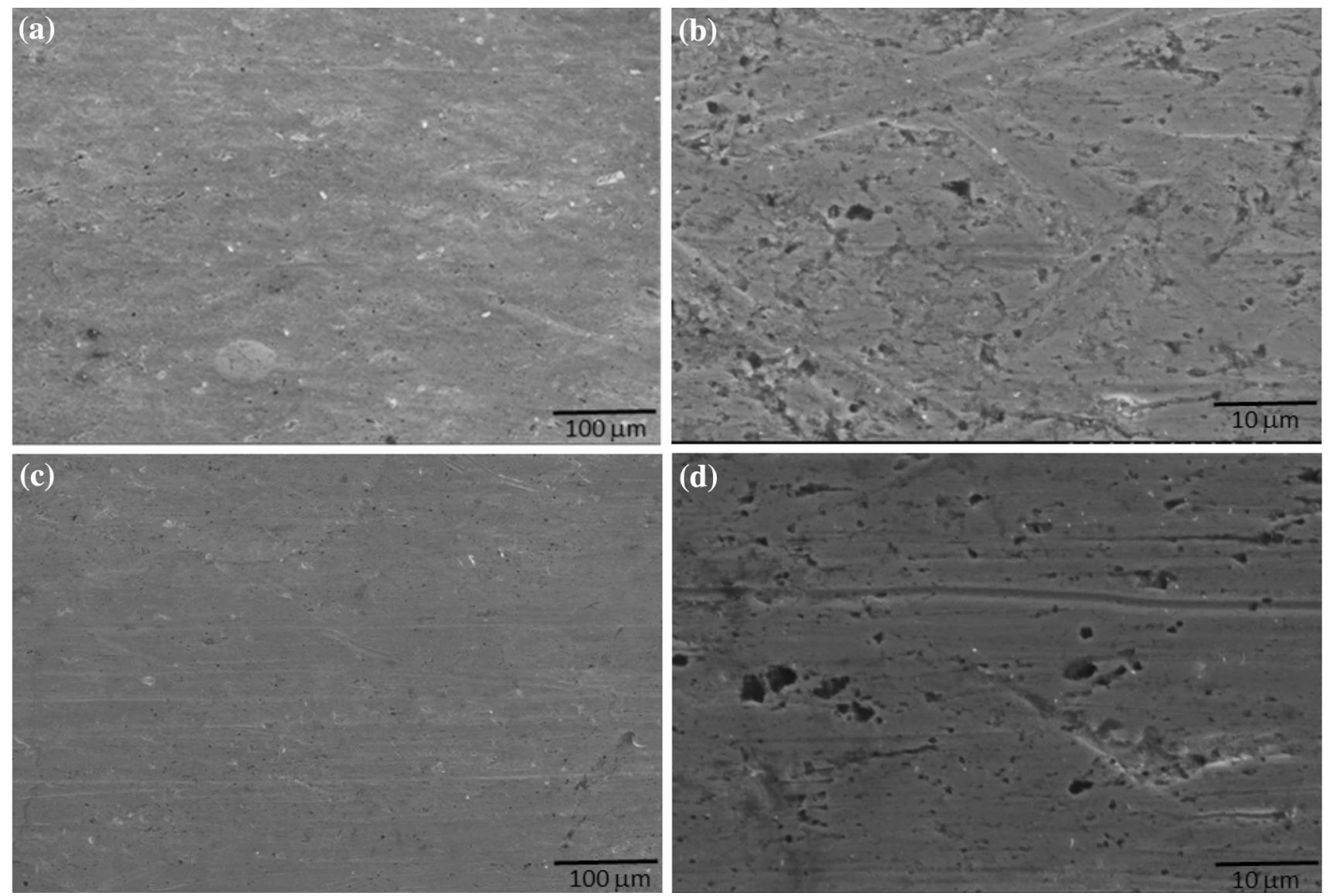

Fig. 5 Surface appearances of a specimen after testing in $3.5 \% \mathrm{NaCl}$ slurry with $10 \mathrm{wt} \%$ sands under sliding speed of $48 \mathrm{rpm}$ (a, b without CP; c, $\mathbf{d}$ under cathodic protection)

plastic deformation due to micro-plowing or wedging could be observed at higher magnification. In all the cases, small pits can be observed. The pits on the specimens tested under CP appear to be more defined and deeply developed (as shown in respective micrographs in Figs. 5, 6). Pitting initiation is possible under abrasion due to associated micro-surface deformation, as it is well known that pits can preferentially nucleate/form along scratches or plastically deformed regions for iron [29, 30]. Under CP, it is believed that, overall, general corrosion is depressed, where the likelihood of sustained growth of pits (once initiated) is higher; in contrast, if general corrosion prevails, small shallow pits could be eliminated by uniform corrosion, and the likelihood of sustained growth of pits will be lower.

\subsection{Mechanisms of Slurry Abrasion-Corrosion}

In general, the Miller test is a low-stress abrasion process. When test was conducted under $\mathrm{CP}$, the dominant 

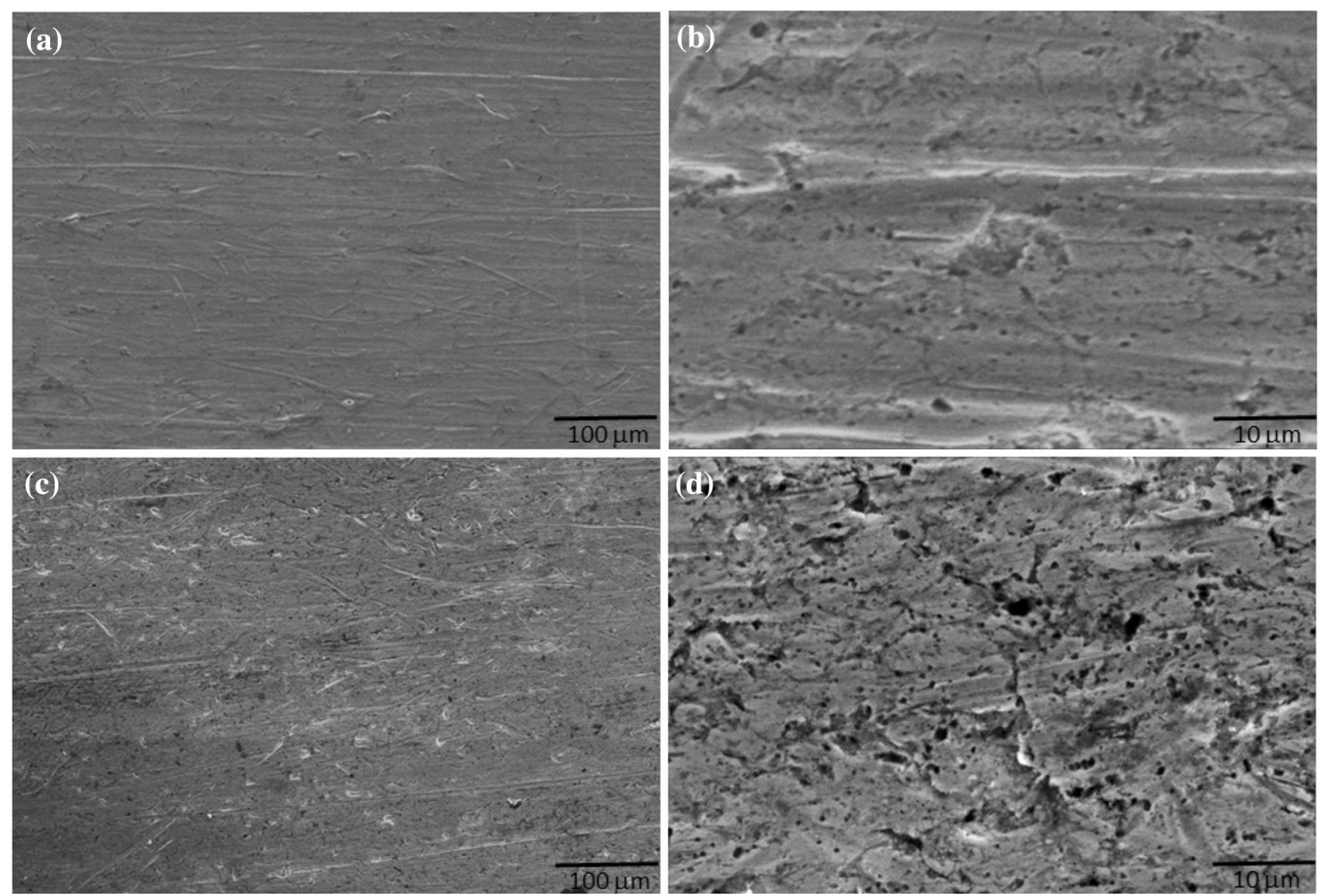

Fig. 6 Surface appearances of a specimen after testing in $3.5 \% \mathrm{NaCl}$ slurry with $50 \mathrm{wt} \%$ sands with sliding speed of $16 \mathrm{rpm}(\mathbf{a}$, b without cathodic protection; $\mathbf{c}, \mathbf{d}$ under cathodic protection)

mechanical damage mechanism for QT 100 steel is microplowing and/or micro-wedging (see [31] for definitions). It should be mentioned that, as shown in Fig. 7, Ottawa sand is a rounded quartz grain sand as detailed in ASTM G65 [32] and, therefore, micro-cutting [31] should be less significant under current low stress abrasion condition. To a certain degree, it may play a minor role at the initial state of each test while the sand particles are still fresh and more angular.

When test is conducted in the slurry of $\mathrm{NaCl}$ solution without $\mathrm{CP}$, corrosion occurs and, especially, it will interact actively with the abrasion process causing synergistic effect. Abrasion (plowing/wedging) will generate a plastic deformation layer (resulting in higher state of disorder and larger microscopic surface area [33]) and create fresh active metal surfaces (by removing protective oxide products/film), leading to enhanced corrosion loss. In addition, continuing relative movement of the specimen surface against the electrolyte (the slurry) and interactions of sand particles with the specimen surface can also lead to increased mass transfer rate [33] and to reduced local polarization resistance (by

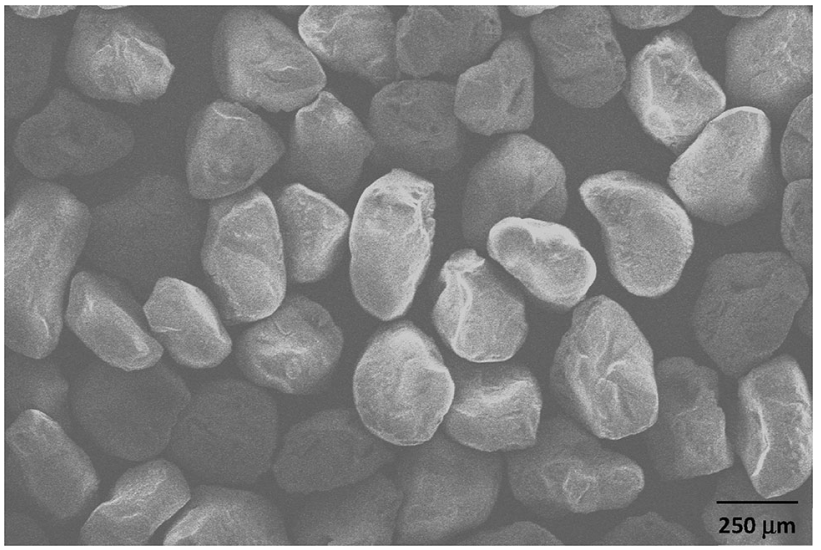

Fig. 7 SEM micrograph of the Ottawa sand particles used for the present study

breaking the equivalence of double layers), further promoting electrochemical corrosion. As reported above, however, the contribution of pure corrosion to the mass loss could be neglected; therefore, it could be fairly expected that, despite of potential factors of corrosion enhancement listed above, 
electrochemical corrosion rate alone plays an insignificant/ negligible role overall.

On the other hand, corrosion can accelerate wear damages, leading to corrosion-enhanced abrasion. In any wear process, material loss is the result of wear debris generation and removal from the wear surface. In the model proposed by Jiang et al. [20, 23], the wear debris generation has been argued to be essentially a low-cycle fatigue process involving the micro-crack initiation and propagation. This is especially true in the present case where micro-cutting is presumably non-dominant; recurrent micro-plowing and micro-wedging result in repeated local surface deformation, leading to fatigue damage. Corrosion has two major effects that can enhance wear damages: (a) localized corrosion can potentially increase the number of micro-crack initiation sites and (b) corrosion at a crack tip can accelerate the crack propagation, both increasing the generation rate of wear debris. The promoting effects of corrosion on wear-debris generation could be reduced/eliminated by applying $\mathrm{CP}$.

It should be noted that the above-mentioned synergistic effect becomes less significant in less corrosive slurry of DI water. More detailed studies on the characteristics and mechanisms of slurry abrasion corrosion of the QT 100 steel and the effects of various working/testing conditions are not the focus of this publication but will be the subject of a further study.

\section{Conclusions}

A methodology has been developed to study the abrasioncorrosion synergism in slurry abrasion by incorporating an in situ three-electrode electrochemical cell to a Miller tester. The following conclusions can be drawn from this investigation:

- Preliminary experimental investigation using the methodology on QT 100 steel indicates that the slurry abrasion corrosion and the synergy can be effectively investigated.

- Cathodic protection (at $0.5 \mathrm{~V}$ more negative to the open circuit potential) employed in the present study is generally effective in eliminating the corrosion effect during slurry abrasion testing, allowing a reliable measurement of pure abrasion component for analyzing abrasion-corrosion synergism.

- The abrasive wear rate in slurry abrasion is dependent on solid concentration in the slurry, slurry corrosivity, and sliding speed.

- Corrosion-induced enhancement on slurry abrasion loss rate increases with slurry corrosivity but inversely with sliding speed.

\section{References}

1. Tian BR, Cheng YF (2008) Electrochemical corrosion behavior of X-65 steel in the simulated oil sand slurry. I: effects of hydrodynamic condition. Corros Sci 50:773-779

2. Tang X, Xu LY, Cheng YF (2008) Electrochemical corrosion behavior of X-65 steel in the simulated oil-sand slurry. II: synergism of erosion and corrosion. Corros Sci 50:1469-1474

3. Yu B, Li DY, Grondin A (2013) Effects of the dissolved oxygen and slurry velocity on erosion-corrosion of carbon steel in aqueous slurries with carbon dioxide and silica sand. Wear 302:1609-1614

4. Parent LL, Li DY (2013) Wear of hydrotransport lines in Athabasca oil sands. Wear 301:477-482

5. Jones M, Llewellyn RJ (2009) Erosion-corrosion assessment of materials for use in the resources industry. Wear 267:2003-2009

6. Jones M, Waag U (2011) The influence of carbide dissolution on the erosion-corrosion properties of cast tungsten carbide/Nibased PTAW overlays. Wear 271:1314-1324

7. He DD, Jiang XX, Li SZ, Guan HR (2005) Erosion-corrosion of stainless steels in aqueous slurries - a quantitative estimation of synergistic effects. Corrosion 61:30-36

8. Neville A, Hodgkiess T, Dallas JT (1995) A study of the erosioncorrosion behaviour of engineering steels for marine pumping applications. Wear 186-187:497-507

9. Toma D, Brandl W, Marginean G (2001) Wear and corrosion behaviour of thermally sprayed cermet coatings. Surf Coat Technol 138:149-158

10. Neville A, Reza F, Chiovelli S, Revega T (2004) Assessing MMCs for corrosion and erosion-corrosion applications in the oil sands industry. CORROSION/04, NACE, Paper 04125

11. Neville A, Hodgkiess T, Xu H (1999) An electrochemical and microstructural assessment of erosion-corrosion of cast-iron. Wear 233-235:523-534

12. Clark HM (1993) The influence of flow field in slurry erosion. Wear 152:223-240

13. Souza VAD, Neville A (2007) Aspects of microstructure on the synergy and overall material loss of thermal spray coatings in erosion-corrosion environments. Wear 263:339-348

14. Yang Y, Cheng YF (2012) Parametric effects on the erosioncorrosion rate and mechanism of carbon steel pipes in oil sands slurry. Wear 276-277:141-148

15. Rajahram SS, Harvey TJ, Wood RJK (2009) Erosion-corrosion resistance of engineering materials in various test conditions. Wear 267:244-254

16. Jana BD, Stack MM (2005) Modelling impact angle effects on erosion-corrosion of pure metals: construction of materials performance maps. Wear 259:243-255

17. Meng H, Hu X, Neville A (2007) A systematic erosion-corrosion study of two stainless steels in marine conditions via experimental design. Wear 263:355-362

18. Mischler S, Debaud S, Landolt D (1998) Wear-accelerated corrosion of passive metals in tribocorrosion systems. J Electrochem Soc 145:750-758

19. Jemmely P, Mischler S, Landolt D (2000) Electrochemical modeling of passivation phenomena in tribocorrosion. Wear 237:63-76

20. Jiang J, Stack MM (2006) Modelling sliding wear: from dry to wet environments. Wear 261:954-965

21. García I, Drees D, Celis JP (2001) Corrosion-wear of passivating materials in sliding contacts based on a concept of active wear track area. Wear 249:452-460

22. Landolt D, Mischler S, Stemp M, Barril S (2004) Third body effects and material fluxes in tribocorrosion systems involving a sliding contact. Wear 256:517-524 
23. Jiang J, Stack MM, Neville A (2002) Modelling the tribo-corrosion interaction in aqueous sliding conditions. Tribol Int 35:669-679

24. Guo HX, Lu BT, Luo JL (2005) Interaction of mechanical and electrochemical factors in erosion-corrosion of carbon steel. Electrochim Acta 51:315-323

25. Barik RC, Wharton JA, Wood RJK, Stokes KR (2009) Electromechanical interactions during erosion-corrosion. Wear 267:19001908

26. Jiang J, Tufa KY (2013) The effect of corrosion on slurry abrasion of wear resistant steels. In: Blau PJ, Celis J-P, Drees D (eds) Tribo-corrosion: research, testing, and applications. ASTM Selected Technical Papers STP1563, p. 66-87

27. ASTM G75-07 (2007) Standard test method for determination of slurry abrasivity (Miller number) and slurry abrasion response of materials (SAR number). doi:10.1520/G0075-07

28. ASTM G119-09 (2009) Standard guide for determining synergism between wear and corrosion. ASTM international, West Conshohocken. doi:10.1520/G0119-09
29. Vetter KJ, Strehblow HH (1974) Pitting corrosion in an early stage and its theoretical implications. In: U.R. Evans (ed) Conference on localized corrosion. NCE Houston, Williamsburg 1971, p 240-251

30. Weil KG, Menzel D (1959) Die Einwirkung von Halogenionen auf passives Eisen (The action of halide ions on passive iron). Z Elektrochem 63:669-673

31. Tylczak JH (1992) Abrasive wear, ASM handbook, vol 18. ASM international, Almere, pp 184-190

32. ASTM G65 (2010) Standard test method for measuring abrasion using the dry sand/rubber wheel apparatus. doi:10.1520/G006504R10

33. Barker KC, Ball A (1989) Synergistic abrasive-corrosive wear of chromium containing steels. Br Corros J 24:222-228 